\title{
EVALUATION OF THE SPECIFIC PHYSICAL DEVELOPMENT OF THE CYCLISTS AT THE AGE OF 13 TO 14 YEARS
}

\author{
Iv. Kolev* \\ Department „Technical and Ice Sports“, Coaches Faculty, National Sports Academy „Vassil Levski“, \\ Sofia, Bulgaria
}

\begin{abstract}
Ascending level of sport performance in cycling and immense competition in the struggle of world hegemony in this sport require continuous quality improvement and efficiency of educational and training processes. For the purpose of the study was conducted assessing of the level of indexes presenting physical development and specific performance of all respondents (13-14-year-old).

Results and discussion. The use of evaluation (through sigmal method) allows comparing the level of all monitored indexes, regardless of the different measuring units, and on this basis to determine the highlights for future training process for each respondent individually. For solving the purpose and objectives of the following study, individual results of each respondent are assessed based on average level results of each index included in the test battery for selection and evaluation of physical development and specific sport performance. Conclusions. The group of 13-14-year-olds as a whole, is well selected, but the possibilities of 6 children included in it currently does not meet the specific requirements of sport cycling. We need to be much effort in working with these children, the highlights are aimed at developing the signs, which estimates $\mathrm{T}$ are lowest.
\end{abstract}

Key words: cycling, study, indexes, value

\section{INTRODUCTION}

The sports' score (sports performance) is an expression and function of a long standing purposefully organized and skillfully managed sports workout that every human being, in our case the athlete, has a relatively autonomous biological system with probabilistic nature of behavior (1).

World hegemony require continuous improvement of quality and effectiveness of teaching and training and higher level of athletic performance in the cycling sports.

Sports achievement should be seen as a complex multi-factoral phenomenon, whose dynamics in time reveals the cumulative impact of biological, social, economic, technological, and other factors sport education and other practices (2).

\footnotetext{
*Correspondence to: Ivan Kolev, National Sports Academy ,Vassil Levski", Coaches Faculty, Department ", Technical and Ice Sports ", Studentski grad, Acad. Stefan Mladenov 21 str., 1700 Sofia, Bulgaria,kolevnsa@abv.bg
}

As a result, a number of accumulated and unresolved problems in recent years, educational and training process with young athletes is characterized by significantly lowering the quality (3). Mass sport in postcomunist Bulgaria is not a State's priority that is way the selection and the organization of sports activities is not very easy (4). The reason for this is disturb coordination and interoperability between sport organizations, sports' schools and children's centers combined in making the selection and development of sports talent of students-athletes. Sports clubs have limited preparatory work with groups that are fundamental units of attracting and selecting talented children. There are no mechanisms to diagnose physical abilities, and exploring the interests of applicants for athletes. Covered are centers for applied research in sport, which is also a problem in carrying out the selection and control. Uniform methodologies and programs that underlie the sports programs are outdated. Lack of commitment by the Bulgarian Sports Federation (BSF) to the selection of young 
talents and selection of sports-pedagogical staff (5).

The aim of this study is to improve the system for selection and the opening stage for sports training in cycling by assessing the physical growth and specific performance of 13-14year-olds practicing cyclists.

\section{METHODS}

Subject of research is the system of selection, sports orientation and initial training of young cyclists.

The research aims to explore the physical development, physical, technical and tactical skills of 13-14 year old cyclists from Bulgaria.

Contingent of the study were 20 boys, practicing cycling in sports clubs in the country.

For the purposes of the study was using the following survey methods:

- $\quad$ an overview of the scientific literature;

- anthropometry;

- $\quad$ sports and educational testing.

The enclosed battery test includes 14 indicators, of which:
- Evaluation of physical development - 2 score (+ BMI);

- physical qualification - 7 score;

- specific technical and tactical qualification 5 score.

The results obtained are subjected to mathematical and statistical processing through:

- variational analysis

- sigmalen assessment method.

\section{RESULTS AND DISCUSSION}

For the purpose of the study was conducted assessing the level of observed signs of physical development and specific performance under all tested boys in the population surveyed (13-14 year old cyclists).

As indicated in the methodology for the purpose it is applied sigmalen assessment method.

The use of evaluations allows sigmalnite be compared to the level of all observed signs, regardless of the different units and on this basis to be determined highlights in future training work with each of the surveyed boys.

Figure 1 shows the average scores for each of the observed signs of physical development and specific performance.

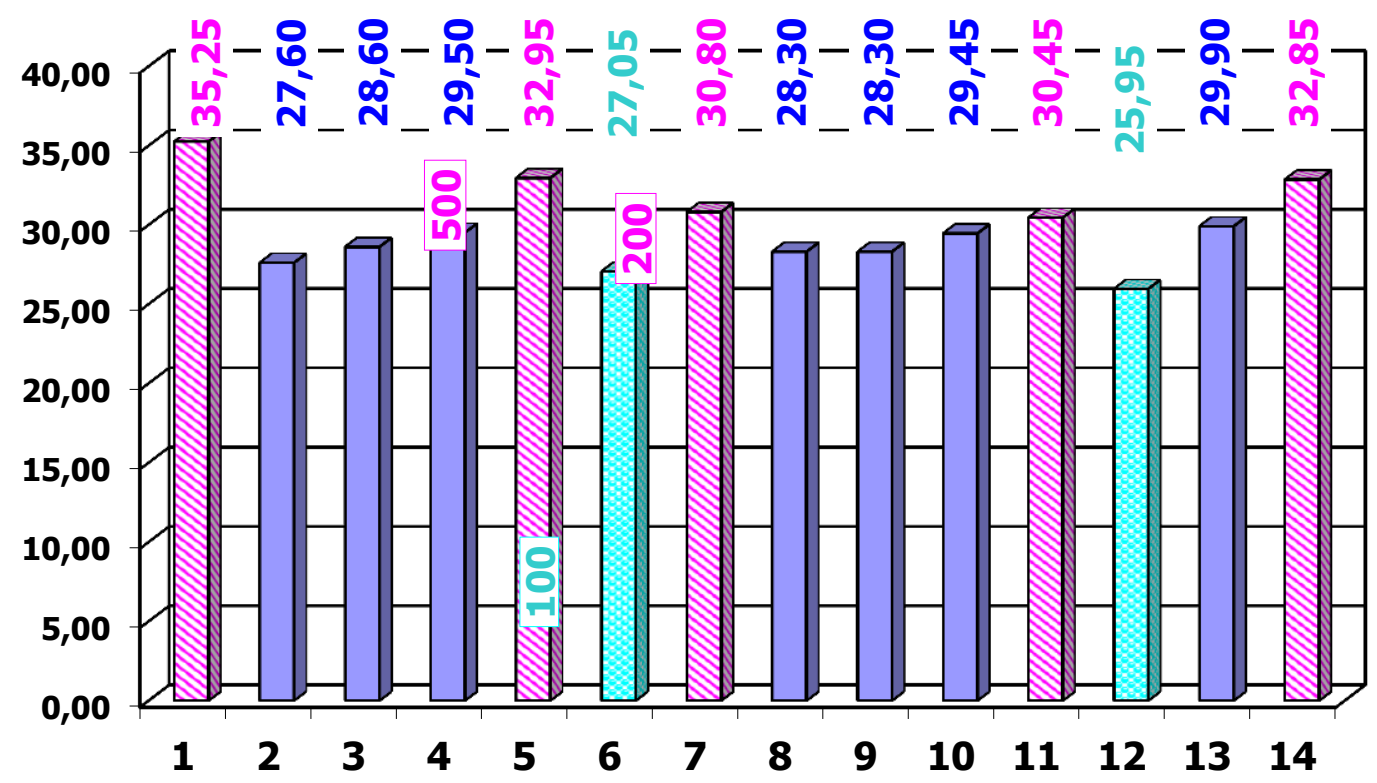

Figure 1. Evaluation of the surveyed signs of physical development and specific performance under 1314 annual bikers

Highest marks (over 30 pts.) Are 5. In this age group maintains high ratings only to sprint capabilities of the boys after low start (indicator $1, \mathrm{~T} 1=35.25$ pts.) And special speed endurance (indicator $7 \mathrm{~T} 7=30.80$ tons.).
The lowest scores in 12th and 6th performance (respectively "vertical jump" and "1000 meters"). This gives grounds to assert that the highest growth in the overall performance of boys in this age group can be achieved if 
efforts in future educational and training work be aimed at developing the signs for which these two indicators carry information:

explosive power of the lower limbs in vertical muscular effort

the ability to cycling at high speed to medium distances.

To solve the purpose and objectives of the study, individual results of each of the surveyed young cyclists are valued based on the average level of each indicator included in the test battery selection and evaluation of physical development and specific performance. The calculated individual assessments sigmalni $\mathrm{T}$ allow us to compare the results of each of the boys as well as horizontally (i.e. the results of the other) and vertically (the personal results in all investigated signs).

$\mathrm{T}$ application assessments by private criterion to optimize the preparation (6), allows to set the highlights of future educational and training work with each of the surveyed young cyclists. The logic of using sigmalnite estimates requires the efforts of both athletes and coaches to be aimed at increasing the level of those signs, which each boy has low scores.
It is clear that to achieve positive results in the future, it is essential to bet on individual work with each of the boys. It is also the coaches to realize that efforts to develop the signs by which assessments are high, you will not have the same effect on the specific performance of young cyclists.

Summary of the young cyclists in the age group 13-14 years are presented in figure 2 . The analysis of Figure 2 shows that in the group of 13-14 year old cyclists have 9 guys who observed a high level of physical development and specific performance. Extremely high (close to the maximum 50 pts.) Are estimates of A. Nikolov and P. Lyubenov, and respectively $44.86 \mathrm{pts}$. to $43.50 \mathrm{pts}$. At the same time, however, observed several low summarized assessments, which means that in this group there are children who do not meet the specific requirements of selection in cycling. These are P. Ljubomirov and E. Krastev. However, in general, it can be considered that the study group of 13-14-yearolds meet the specific requirements of selection in cycling sports.

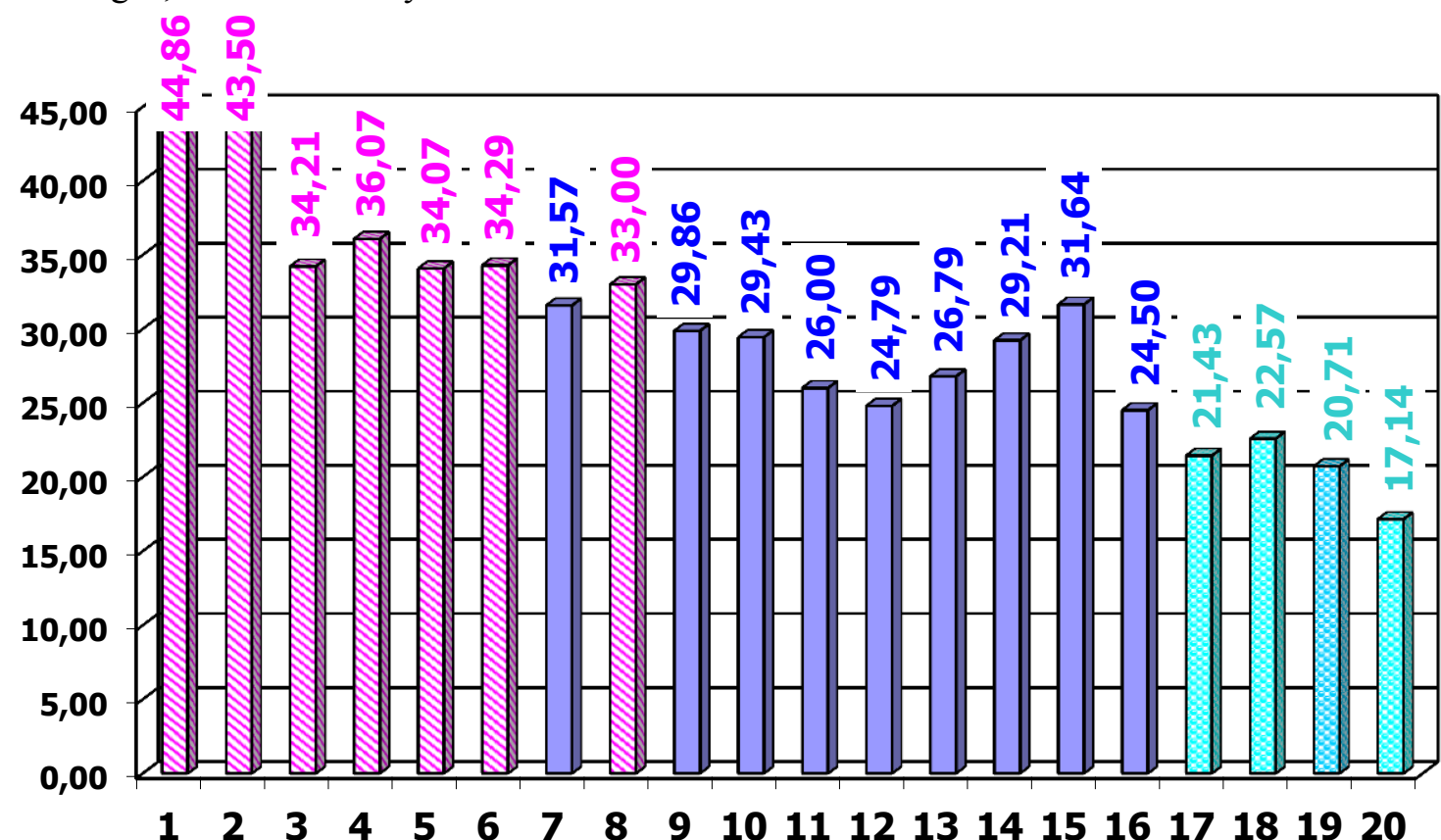

Figure 2. Summary individual assessments of physical development and specific performance of 13-14 year cyclists

All this is proof for the qualified selection of these children to train cycling. The group also has 6 guys in the level of physical development and specific performance is below average ( 25 pts.) For the studied age group. 


\section{CONCLUSIONS}

1. 13-14-years -old cyclists have highest level of development of the following criteria:

- speed capabilities;

- special (cycling) speed endurance;

- explosive power of the lower limbs in vertical muscle strain;

- weight;

2. The lowest scores in 12th and 6th performance speed-power capabilities of the lower limbs ("vertical jump") and special speed endurance rider. ( "1000 meters").

3. The group of 13-14-year-olds as a whole, is well selected, but the possibilities of 6 children included in it currently does not meet the specific requirements of sport cycling.

4. We need to be much effort in working with these children, the highlights are aimed at developing the signs, which estimates $\mathrm{T}$ are lowest.

\section{REFERENCES}

1. Hadjiev, N., D. Dasheva. Stress and adaptation in sports. In Bulgarian. "B - ins". Sofia. 2010.

2. Jelyazkov, Tz., D. Dasheva. Fundamentals of sports training. In Bulgaria. "B - ins". Sofia. 2017.

3. Borukova, M. Improve the system for reception and control the preparation of basketball talent in sports schools in
Bulgaria. Dees. work, NSA Sofia, 2013.

4. Angelova-Igova, B., Milanova-Dikova, P. The body machine. Philosophical alternatives. BAN, Sofia, 2016.

5. Buyuklieva. A. The role of mobile games for the development of physical abilities of 5-7 year olds. Report, NSA, Sofia, 2017.

6. Gyosheva, K., Carov., K., Carova, R. Basketball-control system evaluation and optimization of the sports training (girls and boys - 13-15 years). In Bulgaria. NSA. Sofia. 1990.

7. Brogli, Y. Introduction to the theory and practice of controlling factors of sports achievement. In Bulgarian. Sofia. 2012.

8. Jelyazkov, Tz. Methodological foundations of management and optimisation of the sports training for highly skilled athletes. Dees. work. Sofia, 1978.

9. Kolev, I. System for selection of sports cyclists. NSA press, Sofia, 2012.

10.Kolev, I. Fundamentals of selection and orientation in cycling. Dees. work,. NSA. In of Bulgarian. Sofia. 2016.

11. Milanova, P. Study of physical fitness in 14-15 old students, Sp. i N. 1, Sofia, 2013.

12.Carova. R. Problems of control in basketball. In Bulgarian. "B - ins"., Sofia. 2013. 